\title{
Anatomia de espécies anfíbias de Cyperaceae de lagoas do semi-árido, BA, Brasil ${ }^{1}$
}

\author{
Kelly Regina Batista Leite ${ }^{2}{ }^{5}$, Flávio França ${ }^{3}$ e Vera Lúcia Scatena ${ }^{4}$
}

Recebido em 13/06/2008. Aceito em 26/11/2008

RESUMO - (Anatomia de espécies anfíbias de Cyperaceae de lagoas do semi-árido, BA, Brasil). Foi estudada a anatomia de raízes, rizomas, folhas e escapos de Cyperus odoratus L., Oxycaryum cubense (Poep. \& Kunth) Lye e Pycreus macrostachyos (Lam.) Raynal (CyperaceaePoales) de lagoas do semi-árido da Bahia visando caracterizar anatomicamente as espécies e levantar estruturas adaptativas à forma de vida anfíbia. As espécies apresentam raízes com epiderme unisseriada, córtex com exoderme e lacunas de ar. Os rizomas apresentam feixes vasculares anfivasais ou colaterais no cilindro vascular. As folhas apresentam epiderme unisseriada, com células de parede periclinal externa mais espessada que a interna, estômatos somente na face abaxial, parênquima clorofiliano alternado com lacunas de ar e feixes vasculares colaterais. Os escapos apresentam epiderme unisseriada, feixes de fibras distribuídos perifericamente alternados com parênquima clorofiliano, lacunas de ar e feixes vasculares colaterais. Oxycaryum cubense difere de Cyperus odoratus e Pycreus macrostachyos por apresentar raízes com pêlos longos, rizomas e estolões com feixes vasculares colaterais, folhas com bordo agudo, e ausência de estrutura Kranz nas folhas e escapos. Características anatômicas como: lacunas de ar observadas principalmente nas raízes, células buliformes na face adaxial da epiderme foliar, hipoderme, reduzido número de elementos xilemáticos e pouca lignificação nas paredes celulares dos tecidos nos diferentes órgãos estudados são consideradas importantes na adaptação dessas plantas anfíbias às lagoas temporárias do semi-árido da Bahia.

Palavras-chaves: anatomia ecológica, Cyperaceae, lagoas temporárias, Poales, semi-árido

ABSTRACT - (Anatomy of amphibious Cyperaceae species from lakes in the semi-arid region of Bahia State, Brazil). We examined the anatomy of roots, rhizomes, leaves, and scapes of Cyperus odoratus L., Oxycaryum cubense (Poep. \& Kunth) Lye, and Pycreus macrostachyos (Lam.) Raynal (Cyperaceae-Poales) from temporary lakes in the semi-arid region of Bahia in order to characterize the anatomy and examine structural adaptations to amphibious lifestyle. All species had roots with uniseriate epidermal cells, cortex with exoderm and air canals. The rhizomes had amphivasal or collateral vascular bundles in the vascular cylinder. The leaves had uniseriate epidermal cells with external periclinal cell walls thicker than the inner walls, stomata on the abaxial leaf surface, chlorenchyma alternating with air canals, and collateral vascular bundles. The scapes had uniseriate epidermal cells, fibrous groups distributed peripherally, alternating with chlorenchyma, air canals, and collateral vascular bundles. Oxycaryum cubense differs from Cyperus odoratus and Pycreus macrostachyos by having roots with long hairs; rhizomes and stolons with collateral vascular bundles; leaf blades with acute margins, and lacking Kranz structures in leaves and scapes. Anatomic characters such as the presence of large air canals principally in the roots, bulliform cells on the adaxial face of the leaf epidermis, hypodermis, reduced numbers of xylem vascular elements and little lignification of the cell walls of the different plant organs are considered important features in the adaptation of these amphibious plants that inhabit temporary lakes in the semi-arid region of Bahia state.

Key words: Cyperaceae, ecological anatomy, Poales, semi-arid, temporary lakes

\section{Introdução}

A família Cyperaceae está incluída na ordem Poales, no mesmo clado que agrupa as famílias Bromeliaceae, Eriocaulaceae, Juncaceae, Mayacaceae, Poaceae, Rapateaceae, Typhaceae e Xyridaceae entre outras (APG II 2003).

Cyperaceae é uma família cosmopolita, constituindo a terceira maior família em diversidade de espécies entre as monocotiledôneas. Apresenta cerca de 104 gêneros e mais de 5000 espécies, de hábito terrestre ou aquático, formando grandes populações em diversos habitats, principalmente em ambientes abertos e úmidos das regiões tropicais e subtropicais (Goetghebeur 1998). Cerca de 31 gêneros de Cyperaceae contêm espécies aquáticas que apresentam variadas formas de vida (Cook 1996) e colonizam principalmente ambientes lênticos, merecendo especial atenção as espécies encontradas nas lagoas temporárias (França et al. 2003; Matias et al. 2003).

Os ecossistemas aquáticos temporários, conhecidos como alagados, brejos ou áreas inundáveis, são típicos da região Nordeste do Brasil, apresentam-se secos nos períodos de estiagem e retornam ao estado alagado na época das chuvas, podendo apresentar distribuição irregular e escassa de chuvas e em algumas áreas chegar a até 11 meses de estiagem (Maltchik \& Pedro 2001). São caracterizados por apresentar grande diversidade vegetacional, com espécies tolerantes e adaptadas a solos que sofrem inundações sazonais (Nielsen \& Orcutt 1996).

Estudos com espécies de Cyperaceae de ambiente aquático se restringem à listas taxonômicas ou aspectos ecológicos, apresentando alta frequiência de espécies da família nas floras de lagoas temporárias. A alta representatividade dessa família em ambientes aquáticos é devida à presença de rizomas, tubérculos e estolões, que permite maior eficiência na propagação vegetativa (Pott et al. 1989; Bove et al. 2003; França et al. 2003; Matias et al. 2003).

Estudos anatômicos com espécies de Cyperaceae têm se mostrado úteis na taxonomia de vários grupos, principalmente com espécies brasileiras de Hypolytrum

\footnotetext{
Parte da Tese de Doutorado da primeira Autora

2 Universidade Federal da Bahia, Instituto de Ciências Ambientais e Desenvolvimento Sustentável, Barreiras, BA, Brasil

3 Universidade Estadual de Feira de Santana, Departamento de Ciências Biológicas, Feira de Santana, BA, Brasil

${ }^{4}$ Universidade Estadual Paulista, Instituto de Biociências, Departamento de Botânica, Rio Claro, SP, Brasil

5 Autor para correspondência: kellyrbleite@gmail.com
} 
(Alves et al. 2002) e Bulbostylis (Prata et al. 2007). Com espécies aquáticas brasileiras foram desenvolvidos estudos de estruturas anatômicas das brácteas de Cyperus giganteus (Rodrigues \& Estelita 2003) e estudos sobre a atividade meristemática da endoderme de $C$. papyrus (Menezes et al. 2005).

Dentre as várias espécies de Cyperaceae aquáticas, ocorrentes nas lagoas temporárias do semi-árido da Bahia, buscou-se estudar aquelas que apresentam forma de vida anfíbia para tentar entender quais características podem ser consideradas adaptativas que permitem o sucesso das espécies. Cyperus odoratus L., Pycreus macrostachyos (Lam.) Raynal e Oxycaryum cubense (Poep. \& Kunth) Lye, selecionadas para este trabalho pertencem à diferentes gêneros de Cyperoideae e à tribo Cypereae (Goetghebeur 1998), sendo os gêneros Cyperus e Pycreus considerados os mais próximos filogeneticamente. A escolha das espécies de diferentes gêneros de Cyperaceae foi devida à abundância delas nas lagoas temporárias do semi-árido da Bahia e por apresentarem a mesma forma de vida, anfíbia.

Dessa forma, este trabalho objetivou caracterizar anatomicamente os órgãos vegetativos de Cyperus odoratus L., Pycreus macrostachyos (Lam.) Raynal e Oxycaryum cubense (Poep. \& Kunth) Lye (Cyperaceae) ocorrentes em lagoas do semi-árido da Bahia, buscando levantar características adaptativas à forma de vida anfíbia.

\section{Material e métodos}

Espécies de Cyperus odoratus L., Oxycaryum cubense (Poep. \& Kunth) Lye e Pycreus macrostachyos (Lam.) Raynal foram coletadas em cinco lagoas diferentes do semi-árido da Bahia, localizadas entre as coordenadas $12^{\circ} 16^{\prime} 32^{\prime \prime} \mathrm{S}-39^{\circ} 03^{\prime} 22^{\prime \prime} \mathrm{W}$ e $12^{\circ} 10^{\prime} 00^{\prime \prime} \mathrm{S}-39^{\circ} 12^{\prime} 36^{\prime \prime} \mathrm{W}$ no município de Angüera, ao longo da rodovia BA 052 (Estrada do Feijão) em períodos sucessivos de cheia.

As lagoas onde os espécimes foram coletados não apresentam comunicação. São formadas por depressão do relevo e alimentadas por água da chuva, permanecendo cheias por um tempo maior que o período das chuvas, suficiente para o estabelecimento de uma flora rica e com alta diversidade de espécies vegetais (Maltchik 1999; França et al. 2003).

Para a análise anatômica foram utilizadas plantas adultas fixadas em FAA 70! e posteriormente preservadas em álcool etílico 70 ! (Johansen 1940). O material estudado encontra-se depositado no herbário da Universidade Estadual de Feira de Santana (HUEFS): Cyperus odoratus: Leite et al. 477; Leite 486; Leite \& França 495; Leite \& França 519; Leite \& França 520; Leite \& França 521. Oxycaryum cubense: Leite et al. 475; Leite \& França 522; Leite \& França 523; Leite \& França 524; Leite \& França 525. Pycreus macrostachyos: Leite 486A; Leite 487A; Leite \& França 496; Leite \& França 500; Leite \& Lessa 507.

A partir do material fixado foram feitas secções nas regiões apical, mediana e basal de raízes, rizomas, estolões, folhas e escapos. Foram utilizados pelo menos três indivíduos de cada espécie. As secções transversais e longitudinais dos diferentes órgãos foram feitas à mão livre, com o auxílio de lâmina de barbear, clarificadas com hipoclorito de sódio a $50 \%$ e submetidas ao processo de dupla coloração com azul de astra e safranina (modificado de Bukatsch 1972 apud Kraus \& Arduim 1997).

Para dissociação da epiderme foliar, foi utilizado o método de Jeffrey (Johansen 1940) cujas porções foram lavadas em água destilada e posteriormente coradas com safranina 1\% (Bukatsch 1972 apud Kraus \& Arduin 1997).
Algumas peças dos diferentes órgãos foram submetidas à desidratação em série etílica e incluídas em historresina Leica [2-hidroxietilmetacrilato] (Feder \& O’Brien 1968). O material incluído foi seccionado em micrótomo rotativo, com $10 \mu \mathrm{m}$ de espessura. As secções anatômicas foram submetidas à coloração com ácido-periódicoreativo de Schiff (PAS) e azul de toluidina (Feder \& O’Brien 1968) e montadas em lâminas permanentes com Entellan.

\section{Resultados}

Cyperus odoratus, Oxycaryum cubense e Pycreus macrostachyos são plantas herbáceas, anfíbias, tolerantes à seca, com rizoma vertical, folhas lineares, filotaxia espiralada, formando touceiras (Fig. 1, 4, 7). O rizoma na porção basal é envolvido por bainhas de folhas velhas, de onde crescem as raízes adventícias (Fig. 2, 5, 8) e na porção apical, crescem folhas jovens e escapos (Fig. 1, 4, 7). Oxycaryum cubense apresenta estolão que cresce a partir do rizoma (Fig. 4).

A região mediana dos escapos, em secção transversal, apresenta formato triangular (Fig. 3, 6 e 9). Internamente à epiderme, ocorrem feixes de fibras de esclerênquima. Em Oxycaryum cubense (Fig. 6) esses feixes estão localizados próximos entre si e o escapo é fistuloso. Ocorre maior proporção de aerênquima em $O$. cubense e Pycreus macrostachyos (Fig. 6 e 9) quando comparados visualmente a Cyperus odoratus (Fig. 3).

As raízes das espécies estudadas, em secção transversal, apresentam epiderme, córtex heterogêneo e cilindro vascular (Fig. 10, 13, 17). A epiderme é unisseriada, com células de paredes finas (Fig. 11, 17, 18). Os pêlos absorventes são abundantes e alongados em Oxycaryum cubense (Fig. 14).

O córtex é heterogêneo e apresenta-se dividido em externo, mediano e interno. O córtex externo é constituído pela exoderme, que apresenta células hexagonais, com paredes levemente espessadas (Fig. 10-11, 13-14, 17-18).

O córtex mediano ocupa a maior porção das raízes. É formado por dois tipos distintos de células: aquelas arredondadas, pequenas, formando de uma a três fileiras de células, intercaladas por células maiores, braciformes (Fig. 10, 13, 17).

As raízes de todas as espécies, no estágio inicial de desenvolvimento, apresentam células corticais jovens com espaços intercelulares reduzidos e são dispostas em fileiras radiais como evidenciado em Oxycaryum cubense (Fig. 16). À medida que a raiz se desenvolve algumas células arredondadas do córtex mediano tornam-se braciformes e, na maturidade, suas paredes se rompem formando lacunas de ar (Fig. 10, 17). Já as células arredondadas do córtex mediano permanecem com as paredes íntegras formando fileiras longitudinais (Fig. 10 e 17). Observa-se pouca lignificação nas paredes das células do córtex mediano (Fig. 10, 13, 17).

O córtex interno é formado por células parenquimáticas arredondadas, menores do que as demais, células corticais, sem espaços intercelulares (Fig. 10, 12-13, 15, 17, 19). Essas células apresentam paredes levemente espessadas na maturidade. A endoderme é unisseriada, com células de 
formato arredondado a levemente quadrangulares e de paredes finas em Cyperus odoratus (Fig. 10,12) em relação à Oxycarium cubense e Pycreus macrostachyos (Fig. 15, 19).

O pericicloé unisseriado (Fig. 10, 12-13, 15, 19) e apresenta células de paredes finas e formato levemente arredondado . O cilindro vascular tem estrutura poliarca e pode apresentar apenas um (Fig. 13,17) ou vários elementos de metaxilema central (Fig. 12), mas quando comparadas com espécies terrestres, observa-se o número reduzido de elementos xilemáticos em todas as raízes das espécies estudadas (Fig. $12,15,19)$.

Os rizomas das espécies estudadas apresentam epiderme, córtex e cilindro vascular (Fig. 20-26). A epiderme é constituída por células arredondadas e de paredes finas quando assim como nos demais órgãos (Fig. 20, 25). O córtex apresenta células parenquimáticas de paredes finas e de

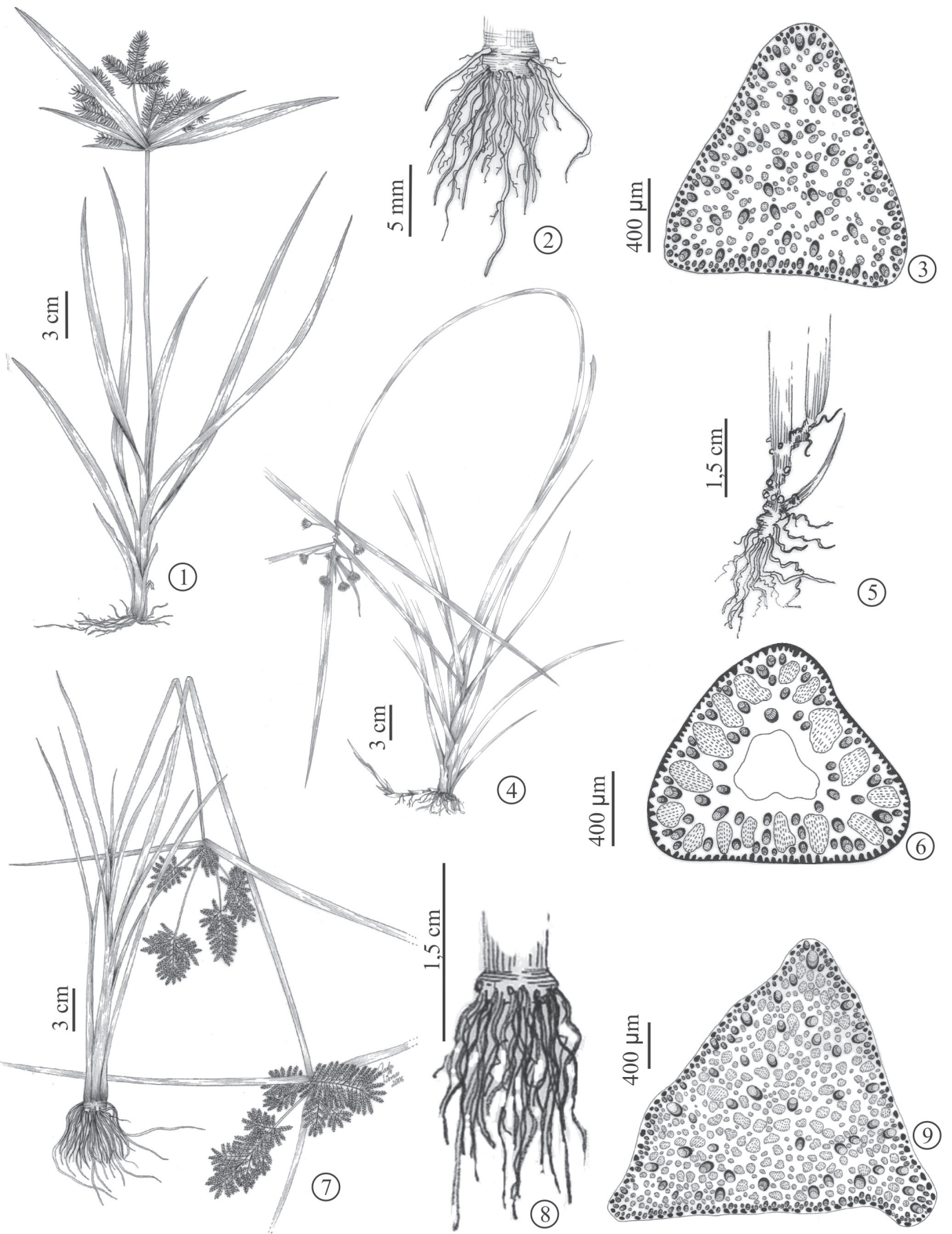

Figuras 1-9. Aspectos morfológicos de espécies de Cyperaceae: 1-3. Cyperus odoratus L. 1. Hábito. 2. Detalhe do sistema subterrâneo. 3. Secção transversal da região mediana do escapo. 4-6. Oxycaryum cubense (Poep. \& Kunth) Lye 4. Hábito. 5. Detalhe do sistema subterrâneo. 6. Secção transversal da região mediana do escapo. 7-9. Pycreus macrostachyos (Lam.) Raynal 7. Hábito. 8. Detalhe do sistema subterrâneo. 9. Secção transversal da região mediana do

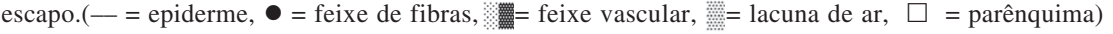


formato arredondado (Fig. 20, 22, 25), podendo apresentar raízes adventícias intracorticais (Fig. 20, 25 - setas). A endoderme é unisseriada, com células arredondadas e de paredes espessadas (Fig. 21-22, 26). O córtex de Oxycaryum cubense (Fig. 22) apresenta amplas lacunas de ar.

O cilindro vascular é delimitado pelo periciclo (Fig. 20-21, 22, 25-26) e apresenta distribuição atactostélica (Fig. 23, 24, 26). É constituído apenas por feixes vasculares anfivasais em Cyperus odoratus (Fig. 21) e Pycreus macrostachyos (Fig. 26) e por feixes vasculares colaterais em Oxycaryum cubense (Fig. 22). Em todos esses feixes vasculares o número de elementos xilemáticos é reduzido (Fig. 21-24, 26).

Oxycaryum cubense apresenta estolão além de rizoma. No estolão, na região do nó (Fig. 23) observam-se plexos vasculares, que irão vascularizar folhas e raízes. Na região do entrenó (Fig. 24) a epiderme é unisseriada. O córtex é formado por células arredondadas, onde estão distribuídos os feixes vasculares colaterais e as lacunas de ar (Fig. 24).

As folhas de todas as espécies de Cyperaceae estudadas, em vista frontal, apresentam células epidérmicas alongadas no sentido longitudinal da lâmina, com paredes levemente sinuosas (Fig. 27-32). As folhas são hipoestomáticas, com estômatos do tipo paracítico, distribuídos em fileiras longitudinais (Fig. 28, 30, 32).

Em secção transversal da folha, a epiderme é uniestratificada com células epidérmicas da face adaxial maiores em relação às da face abaxial (Fig. 33-42, 44) e com paredes periclinais externas mais espessadas que as internas (Fig. 33-42). O bordo foliar é arredondado em Cyperus odoratus e Pycreus macrostachyos (Fig. 33, 35) e agudo em Oxycaryum cubense (Fig. 34) com esclerênquima adjacente à epiderme, nas três espécies estudadas.

Nas espécies estudadas, na face adaxial da epiderme, principalmente na altura da nervura central, ocorrem células buliformes maiores do que as demais células epidérmicas (Fig. 36, 38-39, 41), estando ausentes apenas na região basal das lâminas (Fig. 42).

No mesofilo, próximo à epiderme, ocorrem feixes de fibras de esclerênquima distribuídos ao longo de toda a extensão da lâmina foliar (Fig. 33-42). O mesofilo apresenta hipoderme voltada à face adaxial (Fig. 33-42), com parênquima clorofiliano paliçádico voltado à face abaxial em Oxycaryum cubense (Fig. 38-40) e disposto de forma radiada em torno dos feixes vasculares em Cyperus odoratus (Fig. 36-37) e Pycreus macrostachyos (Fig. 41-42, 44). Estas duas últimas espécies apresentam feixes vasculares com anatomia Kranz do tipo "clorociperóide". No mesofilo de todas as espécies ocorre parênquima clorofiliano braciforme (Fig. 37, 41-42), que constitui diafragmas que limitam lacunas de ar (Fig. 43).

Os feixes vasculares das folhas são colaterais (Fig. 33-42, 44), de diferentes tamanhos, envolvidos por bainha dupla. A externa, parenquimática, constitui a endoderme e a interna, de células de paredes espessadas constitui o periciclo. Este último pode envolver completamente os feixes vasculares e formar calotas de fibras junto ao xilema (Fig. 38-40). A redução do número de elementos xilemáticos pode ser facilmente observada (Fig. 36-42, 44). As lacunas de ar ocorrem em toda a extensão do limbo foliar, sempre intercaladas com feixes vasculares ou logo abaixo deles (Fig. 36-42, 44).

Os escapos das espécies de Cyperaceae estudadas, em secção transversal, apresentam epiderme uniestratificada, com células arredondadas (Fig. 52) e de paredes finas (Fig. $48,50,52)$. Os estômatos estão situados levemente acima das demais células epidérmicas (Fig. 52, 53).

No mesofilo, logo abaixo da epiderme ocorrem feixes de fibras de esclerênquima distribuídos em toda a extensão do escapo (Fig. 46-52). O parênquima clorofiliano do tipo paliçádico está situado perifericamente, com três a quatro camadas de células. Em Cyperus odoratus (Fig. 48) e Pycreus macrostachyos (Fig. 52), o parênquima paliçádico apresenta-se radiado em torno dos feixes vasculares, constituindo anatomia Kranz.

Os feixes vasculares são colaterais e distribuídos por todo o parênquima, com maior concentração na periferia do escapo. São envolvidos por fibras pericíclicas de forma parcial (Fig. 47, 51) ou total (Fig. 49). Observa-se redução do número de elementos xilemáticos em comparação com os elementos floemáticos (Fig. 46-52). Logo abaixo do parênquima clorofiliano ocorrem lacunas de ar (Fig. 46, 49, 51). Apenas as células dos feixes de fibras e as que circundam parcial ou totalmente os feixes vasculares apresentam paredes lignificadas (Fig. 47-53).

Corpos silicosos do tipo cônico foram observados na epiderme das folhas (Fig. 45) e dos escapos, além de cristais prismáticos e ráfides, formando idioblastos na região que delimita a lacuna de ar.

\section{Discussão}

As espécies estudadas neste trabalho são macrófitas aquáticas, anfíbias, que ocorrem em lagoas temporárias e que apresentam facilidade de crescimento devido ao eficiente sistema de reprodução vegetativa.

Essas três espécies de Cyperaceae, mesmo pertencendo a gêneros diferentes, apresentam alguns aspectos morfológicos e anatômicos semelhantes. São plantas afetadas por contínua condição de estresse, caracterizada por períodos de chuvas (três a quatro meses) e de seca (oito a nove meses) na região, podendo de acordo com Maltchik \& Pedro (2001) a estação seca chegar a até 11 meses sem chuvas. $O$ estresse pode ser induzido por fatores bióticos e abióticos, traduzindo-se no desenvolvimento de características morfológicas e anatômicas adaptativas, principalmente nos órgãos de absorção e na presença de aerênquima, conforme referido por Nielsen \& Orcutt (1996).

As diferenças anatômicas observadas entre as espécies estudadas, como raízes com pêlos longos, presença de estolão com feixes vasculares colaterais, folhas com bordo agudo e ausência de anatomia Kranz em Oxycarium cubense pode ser entendida por este gênero ser considerado mais distante filogeneticamente de Cyperus e Pycreus, que já pertenceram ao mesmo gênero, Cyperus (Goetghebeur 1998). 
Acredita-se que o sucesso ecológico das espécies estudadas, mesmo submetidas à condição de estresse, deva-se ao fato delas apresentarem sistema caulinar subterrâneo do tipo rizoma, que segundo Sajo \& Castro (2006) é um tipo de caule especializado com função de reserva ou propagação vegetativa.

Nas raízes de Oxycaryum cubense ocorrem pêlos absorventes longos e em abundância que têm a função de absorção, além de atuar na estabilidade da planta. Essa última característica provavelmente está relacionada à forma de vida, pois no início do seu desenvolvimento foi observado na área de coleta que ela é epífita de outras plantas flutuantes como Salvinia sp., Azzola sp., Pistia stratiotes e Eichhornia crassipes e o mesmo já havia sido relatado também por Tur (1971) e Neves et al. (2006). Na fase adulta e na época de
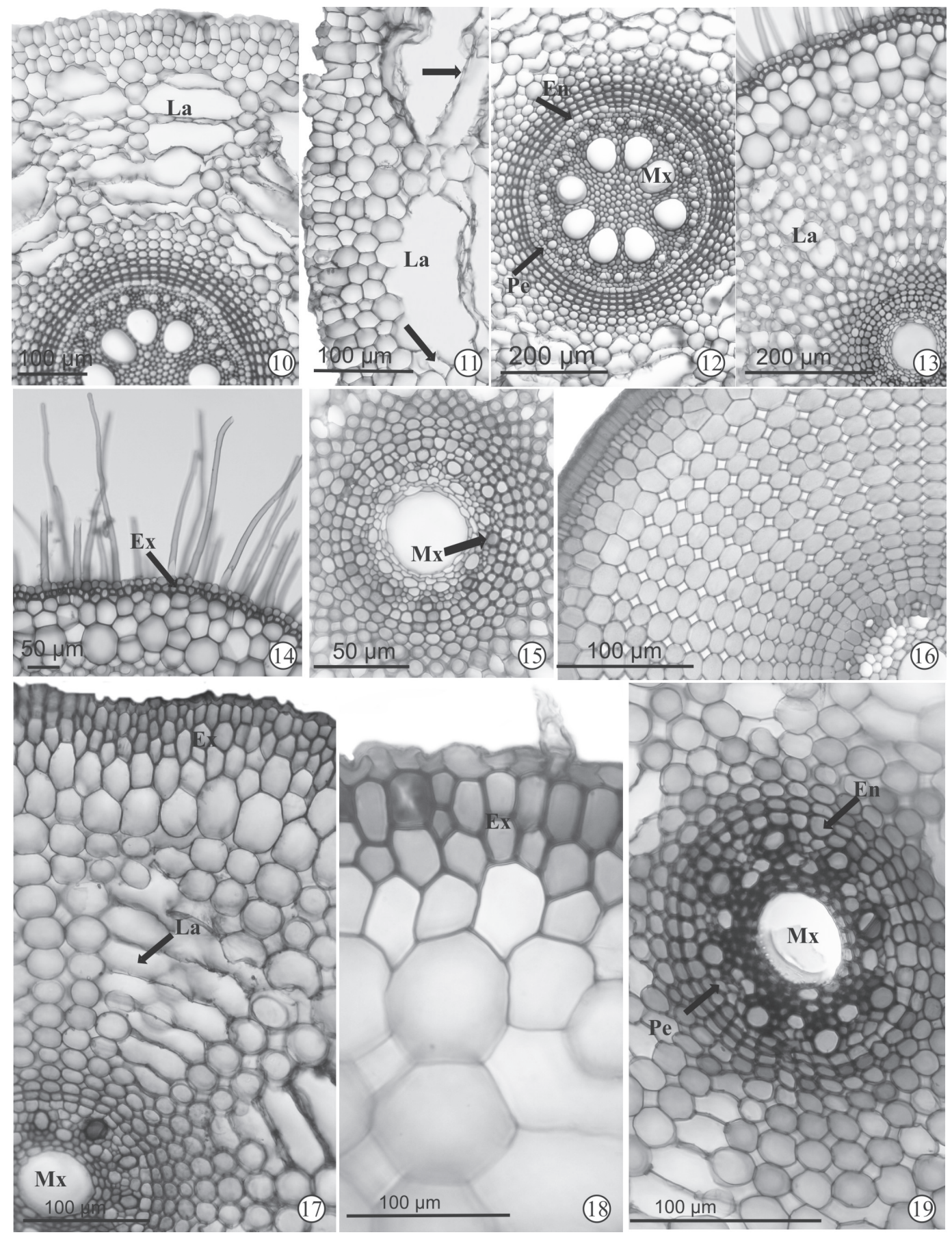

Figuras 10-19. Fotomicrografias de secções transversais da região mediana de raízes de espécies de Cyperaceae: 10-12. Cyperus odoratus L. 10. Aspecto geral. 11. Detalhe da epiderme e exoderme. 12. Detalhe do cilindro vascular. 13-16. Oxycaryum cubense (Poep. \& Kunth) Lye. 13. Aspecto geral - raiz adulta. 14. Detalhe da epiderme e exoderme. 15. Detalhe do cilindro vascular. 16. Aspecto geral - raiz jovem. 17-19. Pycreus macrostachyos (Lam.) Raynal. 17. Aspecto geral. 18. Detalhe da epiderme e exoderme. 19 . Detalhe do cilindro vascular. $(\mathrm{Cb}=$ células braciformes; $\mathrm{Ce}=\mathrm{Córtex}$ externo; $\mathrm{Ci}=\mathrm{Córtex} \mathrm{interno;} \mathrm{Cm}=\mathrm{Córtex} \mathrm{mediano;}$ $\mathrm{En}=$ endoderme; $\mathrm{Ex}=$ exoderme; $\mathrm{La}=$ lacuna de ar; $\mathrm{Mx}=$ metaxilema; $\mathrm{Pe}=$ periciclo). 
seca, essa espécie se fixa ao substrato em decomposição que está na margem da lagoa, comportando-se como anfíbia e deixando, portanto, de apresentar forma de vida epífita (Pott \& Pott 2000).

Em todos os órgãos das espécies estudadas, principalmente nas raízes, observou-se a presença de lacunas de ar que apresentam grande tamanho quando comparadas com a dimensão do córtex e a sobrevivência de plantas que ocorrem em solos alagados é atribuída por Nielsen \& Orcutt (1996), à raízes cujo córtex contém grande quantidade desses espaços de ar. Adaptações ao ambiente aquático podem ser consideradas características genéticas (Davy et al. 1990; Nielsen \& Orcutt 1996) ou fisiológicas (Peterson 1992). Neste último caso, as raízes das plantas
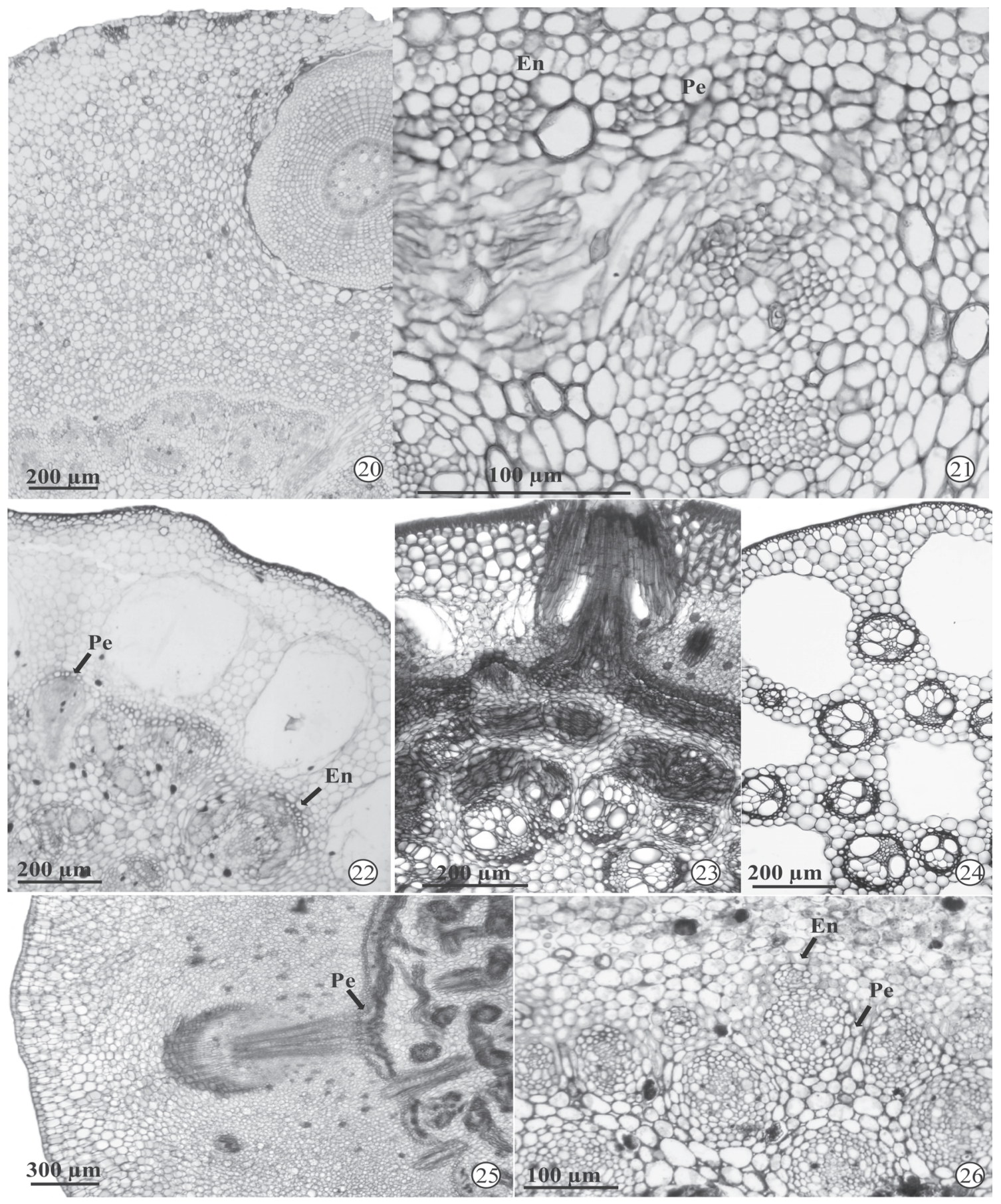

Figuras 20-26. Fotomicrografias de secções transversais da região mediana de rizomas de espécies de Cyperaceae: 20-21. Cyperus odoratus L. 20. Aspecto geral. 21. Detalhe do cilindro vascular. 22-24: Oxycaryum cubense (Poep. \& Kunth) Lye. 22. Aspecto geral do rizoma. 23. Região do nó do estolão. 24. Região do entrenó do estolão. 25-26. Pycreus macrostachyos (Lam.) Raynal. 25. Aspecto geral. 26. Detalhe do cilindro vascular $(\mathrm{En}=\mathrm{endoderme} ; \mathrm{Fl}=\mathrm{floema}$; $\mathrm{Pe}=$ periciclo; $\mathrm{Pv}=$ plexo vascualr; $\mathrm{Ra}=$ raiz adventícia; $\mathrm{Xi}=$ Xilema $)$ 
que crescem em ambientes inundados periodicamente respondem ao estresse com a formação de grande quantidade de lacunas de ar (Nielsen \& Orcutt 1996; Peterson 1992), como observado tanto nas raízes quanto nos rizomas das espécies aqui estudadas.

Para Luxmoore et al. (1972) e Nielsen \& Orcutt (1996) a formação de lacunas de ar em órgãos vegetativos, principalmente raízes e rizomas, mas também em folhas e escapos, pode estar relacionada à temperatura e à intensa luminosidade e na área de coleta das espécies aqui estudadas a temperatura e a luminosidade são elevadas, uma vez que a região semi-árida apresenta cerca de nove meses de verão. Além desses fatores, acredita-se que, para estas espécies, a presença de lacunas de ar também está
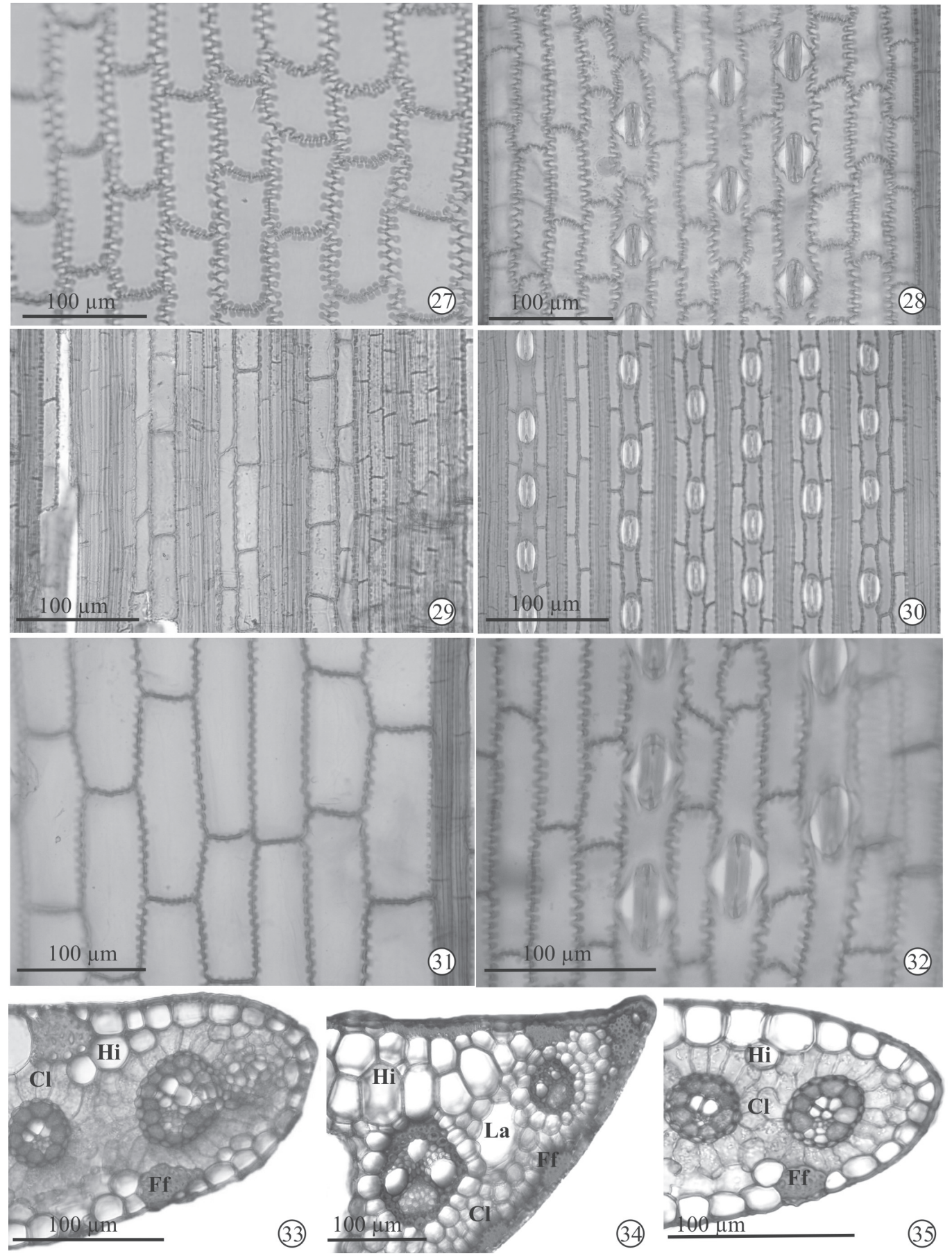

Figuras 27-35. Fotomicrografias de secções paradérmicas e transversais de folhas de espécies de Cyperaceae: 27-32. Vista frontal da epiderme. 27-28. Cyperus odoratus L. 27. Face adaxial. 285. Face abaxial com estômatos. 29-30. Oxycaryum cubense (Poep. \& Kunth) Lye. 29. Face adaxial. 30. Face abaxial com estômatos. 31-32. Pycreus macrostachyos (Lam.) Raynal. 31. Face adaxial. 32. Face abaxial com estômatos. 33-35. Bordo foliar. 33. Cyperus odoratus L. 34. Oxycarium cubense (Poep. \& Kunth) Lye. 35. Pycreus macrostachyos $(\mathrm{Lam}$.$) Raynal (\mathrm{Cl}=$ clorênquima; $\mathrm{Ff}=$ feixe de fibras; $\mathrm{Hi}=\mathrm{hipoderme} ; \mathrm{La}=$ lacuna de ar). 
relacionadas à baixa aeração da água da lagoa. Conforme já relatado para outras plantas de ambientes alagados, a baixa aeração existente na lagoa faz com que o etileno se acumule nas células corticais estimulando a atividade da celulase, que por sua vez, leva à plasmólise e em seguida à morte celular, formando as lacunas de ar (Kawase \& Whitmoyer 1980; Coan et al. 2000).
Essas lacunas promovem a oxigenação através de difusão entre órgãos aéreos e submersos, sendo capazes de transportar $\mathrm{o} \mathrm{O}_{2}$ formado durante a fotossíntese nas folhas para outros órgãos da planta, indicando a continuidade dessas lacunas de ar ao longo de todo o vegetal (Nielsen \& Orcutt 1996) e corroborando o que foi relatado para Polygonun spectabile por Boeger (1994).
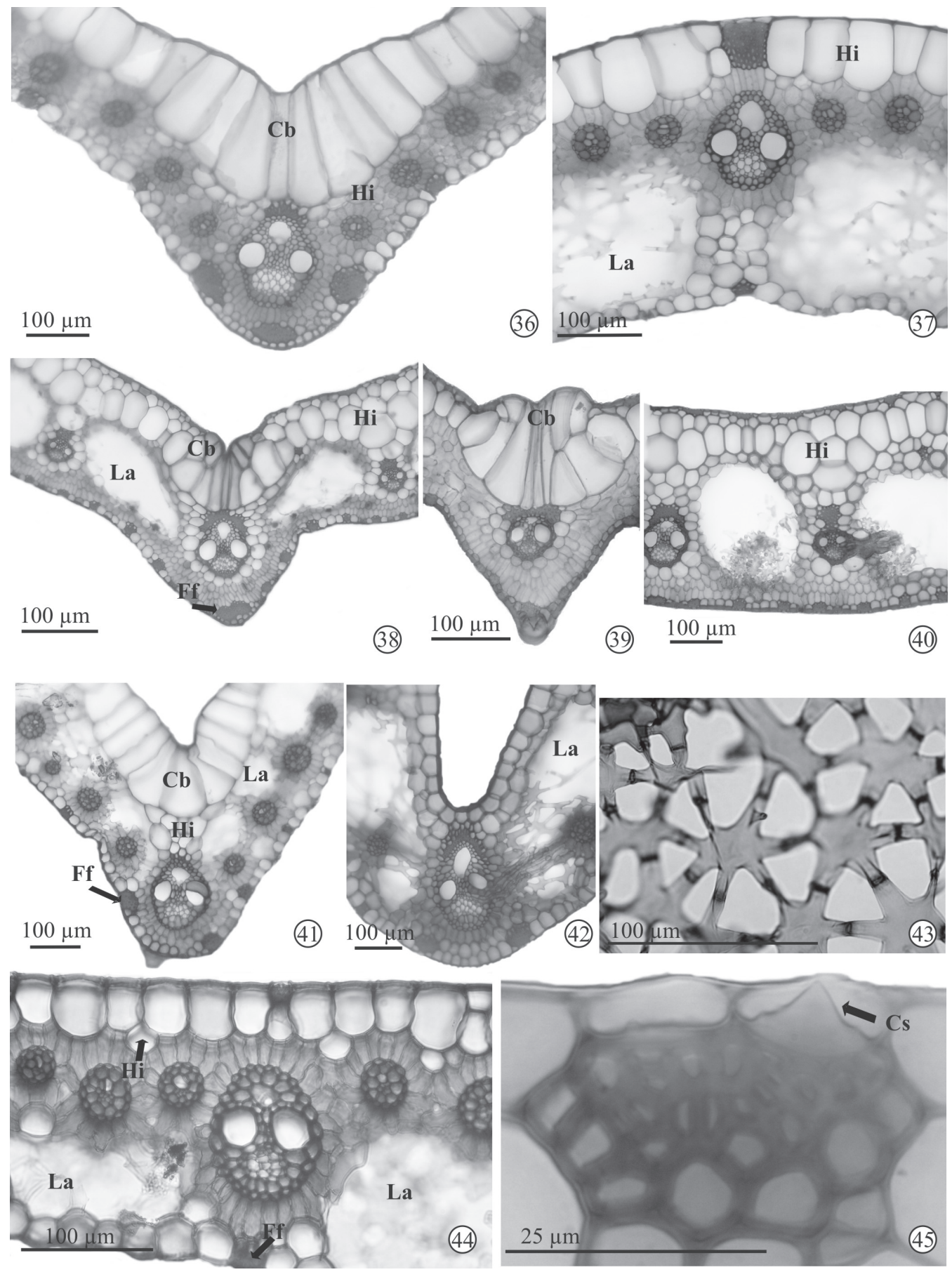

Figuras 36-45. Fotomicrografias de secções transversais de folhas de espécies de Cyperaceae: 36-37. Cyperus odoratus L. - 36. Nervura central. 37. Mesofilo. 38-40. Oxycarium cubense (Poep. \& Kunth) Lye. 38. Nervura central na região basal. 39. Nervura central na região apical. 40. Mesofilo na região mediana. 41-44. Pycreus macrostachyos (Lam.) Raynal - 41. Nervura central na região mediana. 42. Nervura central na região basal. 43. Detalhe do diafragma com células braciformes. 44. Detalhe do mesofilo. 45 . Cyperus odoratus - detalhe do cristal cônico. $(\mathrm{Cbr}=$ células braciformes; $\mathrm{Cb}=\mathrm{célula}$ buliforme; $\mathrm{Cs}=$ corpo silicoso; $\mathrm{Ff}=$ feixe de fibras; $\mathrm{Fp}=$ fibras pericíclicas; $\mathrm{Hi}=$ hipoderme; $\mathrm{La}=$ lacuna de ar). 
A presença de células braciformes, que formam o diafragma, limitam as lacunas de ar nos diferentes órgãos das espécies estudadas e além de serem responsáveis pela condução de gases também atuam de forma mecânica em órgãos submersos conforme o que foi demonstrado em outras plantas aquáticas por Sculthorpe (1967), Kaul (1971) e Fahn (1990).
Nas folhas das espécies estudadas, ocorrem células buliformes que podem estar relacionadas à abertura e fechamento laterais do limbo durante o dia em função da variação da intensidade de luz e temperatura, comum na região semi-árida da Bahia. Esta característica de abertura e fechamento do limbo através de células buliformes foi observada também em espécies de Poaceae (Beal 1886) e

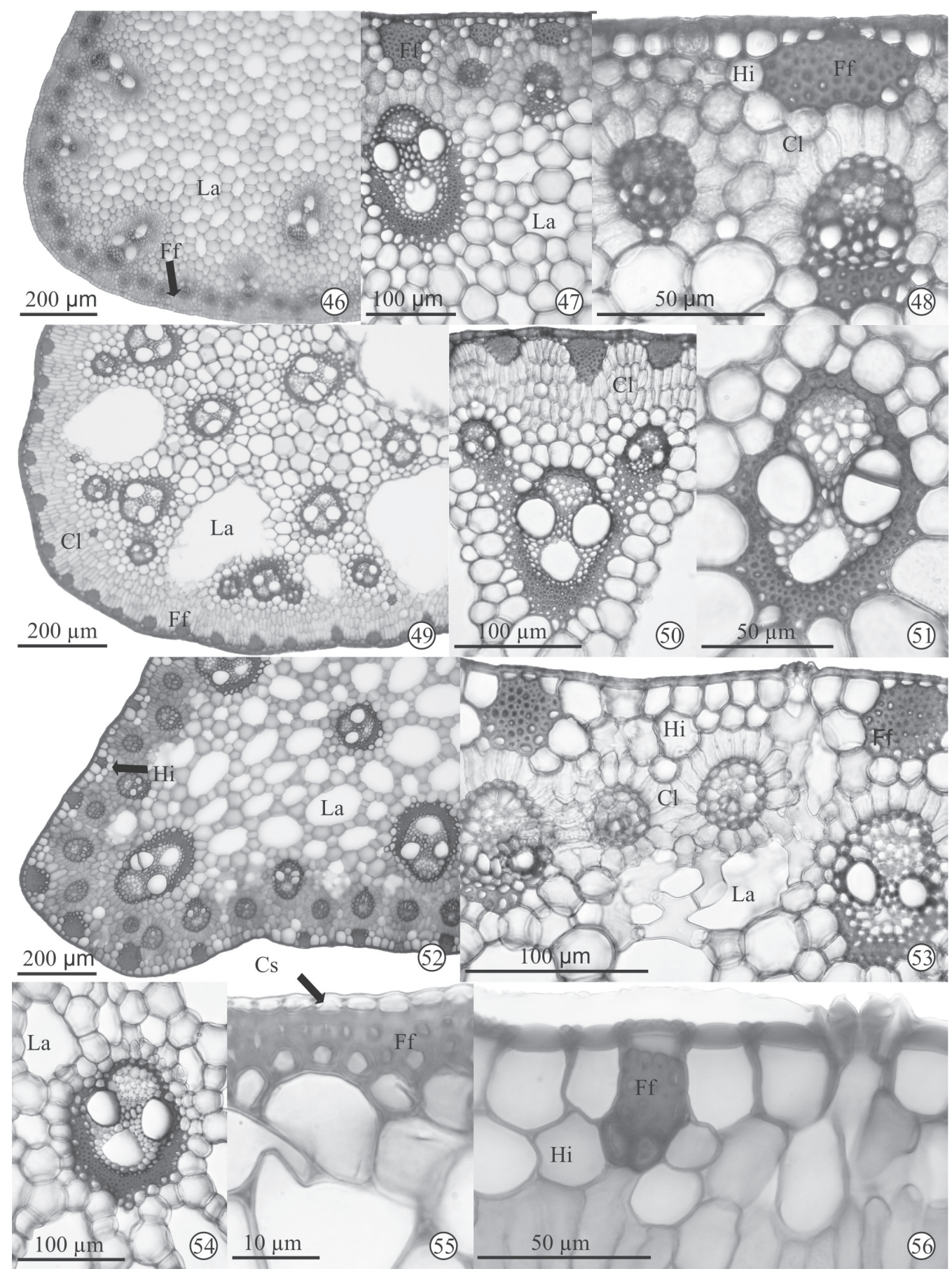

Figuras 46-53. Fotomicrografias de secções transversais da região mediana de escapos de espécies de Cyperaceae: 46-48. Cyperus odoratus L. - 46. Aspecto geral. 47. Detalhe do córtex. 48. Detalhe da epiderme e dos feixes vasculares com estrutura Kranz. 49-50. Oxycarium cubense (Poep. \& Kunth) Lye - 49. Aspecto geral. 50. Detalhe do feixe vascular composto. 51-52. Pycreus macrostachyos (Lam.) Raynal. 51. Aspecto geral. 52. Detalhe do feixe vasculares com estrutura Kranz. 53. Detalhe da epiderme de Pycreus macrostachyos (Lam.) Raynal com estômatos acima das demais células epidérmicas. $(\mathrm{Cl}=$ clorênquima; Es $=$ estômato; $\mathrm{Ff}=$ feixe de fibras; $\mathrm{Fp}=$ fibras pericíclicas; $\mathrm{Hi}=$ hipoderme; $\mathrm{La}=$ lacuna de ar). 
outras Cyperaceae (Mani 1964). De acordo com as observações de campo, nas espécies anfíbias de Cyperaceae aqui estudadas, esse movimento do limbo foliar, se restringe às regiões mediana e apical da lâmina, uma vez que a porção basal está em contato direto com a água. Uma possível interpretação para esta característica é que o movimento foliar ocorre nas horas mais quentes do dia e com maior intensidade luminosa, o que certamente leva a uma diminuição da área da superfície foliar exposta à luz e, assim, reduz a transpiração e a temperatura da folha, mas não dificultando o processo fotossintético.

Nas folhas, logo abaixo da face adaxial da epiderme, ocorre hipoderme parenquimática, constituída por células translúcidas, comum a todas as espécies, embora mais evidente em Oxycaryum cubense. A hipoderme, conforme já descrita por Koyama (1965), para Cyperaceae, pode estar relacionada ao acúmulo de água, constituindo-se, portanto, aqüífera, ajudando assim na manutenção das espécies em períodos de seca.

Em todas as espécies de Cyperaceae estudadas, foram observados corpos silicosos na forma de cristais cônicos na epiderme e ráfides nas células que formam as lacunas de ar. Os cristais cônicos ocorrem sempre na parede periclinal interna das células epidérmicas de folhas e escapos, juntos aos feixes de fibras que estão associados ou não aos feixes vasculares, corroborando o que foi apresentado por Metcalfe (1971) para outras espécies da família.

A presença de cristais nas plantas é considerada por Metcalfe (1971), Prychid \& Rudall (1999) e Lucas et al. (2000) como suporte mecânico e atua na proteção contra a herbivoria, podendo ainda promover a formação de lacunas de ar em plantas aquáticas.

Para Prychid \& Rudall (1999) os cristais de oxalato de cálcio são o produto final do metabolismo celular e representam uma forma de estocar cálcio e ácido oxálico, evitando que, em alta concentração, sejam tóxicos para a célula ou tecido, promovendo o equilíbrio iônico. Essas autoras relataram que pode haver reabsorção do oxalato de cálcio pelas plantas em períodos de baixa concentração deste composto no solo.

Acredita-se que para algumas espécies anfíbias, a passagem da forma terrestre para aquática e vice-versa, envolve ajustes estruturais e fisiológicos, conforme pode ser observado em Cyperus odoratus e Pycreus macrostachyos, que apresentam feixes vasculares com estrutura Kranz, nos quais podem ser observadas duas bainhas em torno dos feixes vasculares, sendo a bainha interna Kranz, interrompida nos feixes de maior calibre (Soros \& Bruhl 2000). Segundo Nielsen \& Orcutt (1996), a maioria das plantas terrestres e aquáticas apresenta fotossíntese $\mathrm{C}_{3}$, sendo encontrados também em espécies aquáticas metabolismo $\mathrm{C}_{4}$ ou $\mathrm{CAM}$ quando sujeitas à altas temperaturas e baixa disponibilidade de água. Este talvez constitua-se, um mecanismo fisiológico de adaptação ao processo fotossintético, concentrador de $\mathrm{CO}_{2}$, desenvolvido pelas espécies Cyperus odoratus e Pycreus macrostachyos.
Nas espécies estudadas os feixes vasculares estão dispostos ao longo de toda a lâmina foliar e na região periférica do escapo, sempre intercalados por amplas lacunas de ar, o que pode indicar a adaptação delas à condição de alagamento. Como apenas Oxycaryum cubense não apresentou anatomia Kranz, acredita-se que essa característica esteja relacionada à sua forma de crescimento, que no início do desenvolvimento é epífita e quando adulta torna-se anfíbia, sendo esta espécie, no entanto, menos adaptada à condição seca da lagoa em relação à Cyperus odoratus e Pycreus macrostachyos.

As espécies de Cyperaceae aqui estudadas, quando comparadas às espécies terrestres de Cyperaceae estudadas por Metcalfe (1971), Alves et al. (2002) e Prata et al. (2007), apresentam redução no número de elementos xilemáticos e reduzida lignificação, característica comum de plantas aquáticas. No caso da reduzida lignificação, a água exerce a função de sustentação em alguns órgãos. No entanto, por serem anfíbias essas espécies apresentam maior lignificação nas paredes de suas células do que outras formas de vida de macrófitas aquáticas, como por exemplo, espécies aquáticas de Eriocaulaceae, Echinodorus (Alismataceae) e Ludwigia (Onagraceae) citados respectivamente por Coan et al. (2002), Matias et al. (2007) e Rodrigues et al. (2007).

Assim, a forma de vida anfíbia das espécies de Cyperaceae aqui estudadas pode ser caracterizada anatomicamente pela presença de lacunas de ar nos diferentes órgãos vegetativos, principalmente no sistema subterrâneo; pela presença de células buliformes, e hipoderme nas folhas; redução do número de elementos xilemáticos e pouca lignificação nas paredes das células nos diferentes órgãos. Essas características são consideradas importantes na adaptação dessas espécies ao ambiente aquático e à forma de vida anfíbia por elas apresentada.

\section{Agradecimentos}

À Fundação de Apoio à Pesquisa do Estado da Bahia - FAPESB, pelo apoio financeiro através de concessão de Bolsa à primeira autora; ao $\mathrm{CNPq}$ pela Bolsa de Produtividade (proc. 301404/2004-6) à terceira autora.

\section{Referências bibliográficas}

Alves, M.V.; Estelita, M.E.M.; Wanderley, M.G.L. \& Thomas, W.W. 2002. Aplicações taxonômicas da anatomia foliar das espécies brasileiras de Hypolytrum Rich. (Cyperaceae). Revista Brasileira de Botânica 25: 1-9.

Angiosperm Philogeny Group (APG). 2003. An update of the Angiosperm Phylogeny Group classification for the orders and families of flowering plants. APG II. Botanical Journal of Linnean Society 141: 399-346.

Beal, W.J. 1886. The bulliform or hygroscopic cells of grasses and sedges compared. Botanical Gazette 11: 321-326.

Boeger, M.R.T. 1994. Adaptações morfológicas e anatômicas de Polygonum spectabile Mart. (Polygonaceae) às inundações na várzea Amazônica. Amazoniana 13: 3-11.

Bove, C.P.; Gil, A.S.B.; Moreira, C.B. \& Anjos, R.F.B. 2003. Hidrófitas fanerogâmicas de ecossistemas aquáticos temporários da planície costeira do estado do Rio de Janeiro, Brasil. Acta Botanica Brasilica 17: 119-135. 
Coan, A.I.; Scatena, V.L. \& Giulietti, A.M. 2000. Anatomia de algumas espécies aquáticas de Eriocaulaceae brasileiras. Acta Botanica Brasilica 16: 371-384.

Cook, C.D.K. 1996. Water plants of world. Amsterdam, SPB Academic Publishing.

Davy, A.J.; Noble, S.M. \& Oliver, R.P. 1990. Genetic variation and adaptation to flooding in plants. Aquatic Botany 38: 91-108.

Fahn, A. 1990. Plant anatomy. Oxford, Pergamon Press.

Feder, N. \& O’Brian, T.P. 1968. Plant microthecnique: some principles and new methods. American Journal of Botany 55: 123-142.

França, F.; Melo, E. de; Góes Neto, A.; Araújo, D.; Bezerra, M.G.; Ramos, H.M.; Castro, I. \& Gomes, D. 2003. Flora vascular de açudes de uma região do semi-árido da Bahia, Brasil. Acta Botanica Brasilica 17: 549-559.

Goetghebeur, P. 1998. Cyperaceae. Pp. 141-190. In: K. Kubitzki; H. Huber, P. Rudall; P. Stevens \& T. Stützel (eds.). The families and genera of vascular plants. Berlin, Spreng-Verlag.

Johansen, D.A. 1940. Plant microtechnique. New York, McGraw Hill Book Co.

Kaul, R.B. 1971. Diafragms and aerenchyma in Scirpus validus. American Journal of Botany 58: 808.

Kawase, M. \& Whitmoyer, R.E. 1980. Aerenchyma development in waterlogged plants. American Journal of Botany 67: 18-22.

Koyama, 1965. Interrelationships between the tribes Lagenocarpeae and Sclerieae (Cyperaceae). Bulletim Torrey Botanical Club 92: $250-265$.

Kraus, J.E. \& Arduin, M. 1997. Manual básico de métodos em morfologia vegetal. Rio de Janeiro, Edur.

Lucas, P.W.; Turner, I.M.; Dominy, N.J. \& Yamashita, N. 2000. Mechanical defences to herbivory. Annals of Botany 86: 913920 .

Luxmoore, R.J.; Sojka, R.E. \& Stolzy, L.H. 1972. Root porosity and growth responses of wheat to aeration and light intensity. Soil and Science 113: 354-357.

Maltchik, L. 1999. Inventory of brazilian semiarid shallow lakes. Anais da Academia Brasileira de Ciências 71: 801-808.

Maltchik, L. \& Pedro, F. 2001. Responses of aquaticmacrophytes to disturbance by flash floods in a brazilian semiarid intermittent stream. Biotropica 33: 566-572.

Mani, A.P. 1964. Bulliform cells in Cyperus. Science and Culture 30: $241-242$

Matias, L.Q.; Amado, E.R. \& Nunes, E.P. 2003. Macrófitas aquáticas da lagoa Jijoca de Jericoacoara, Ceará, Brasil. Acta Botanica Brasilica 17: 623-623.

Matias, L.Q.; Soares, A. \& Scatena, V.L. 2007. Systematic consideration of petiole anatomy of species of Echinodorus Richard (Alismataceae) from north-eastern Brazil. Flora 202: 395-402.
Menezes, N.L.; Silva, D.C.; Arruda, R.C.O.; Mello-de-Pinna, G.F.; Cardoso, V.A.; Castro, N.M.; Scatena, V.L. \& Scremin-Dias, E. 2005. Meristematic activity of the endodermis and the pericycle in the primary thickening in monocotyledons. Considerations on the "PTM". Anais da Academia Brasileira de Ciências 77: 259-274.

Metcalfe, C.R. 1971. Anatomy of the monocotyledons. Cyperaceae. v.V. Oxford, Claredon Press.

Neves, E.L.; Leite, K.R.B.; França, F. \& Melo, E. 2006. Plantas aquáticas vasculares em uma lagoa de planície costeira no município de Candeias, Bahia, Brasil. Sitientibus - Série Ciências Biológicas 6: 24-29.

Nielsen, E.T. \& Orcutt, D.M. 1996. Physiology of plants under stress abiotic factors. United States of America, John Wiley \& Sons, Inc.

Peterson, R.L. 1992. Adaptations of root sstructure in relation to biotic and abiotic factors. Cannadian Journal of Botany 70 661-675.

Pott, V.J.; Bueno, N.C.; Pereira, R.A.C.; Sallis, S.M. \&Vieira, N.L. 1989. Distribuição de macrófitas aquáticas numa lagoa na Fazenda Nhumirim, Nhecolândia, Pantanal, MS. Acta Botanica Brasilica 3: $153-168$

Pott, V.J. \& Pott, A. 2000. Plantas aquáticas do pantanal. Brasília, Embrapa.

Prata, A.P.; Menezes, N.L.; Mazzoni-Viveiros, S.C.; Wanderley, M.G.L. \& Thomas, W.W. 2007. Anatomia do escape e rizoma de espécies brasileiras de Bulbostylis Kunth (Cyperacae). Revista Brasileira de Botânica 30: 245-256.

Prychid, C.J. \& Rudall, P.J. 1999. Calcium oxalate crystals in Monocotyledons: a review of their structure and systematic. Annals of Botany 84: 725-739.

Rodrigues, A.C. \& Estelita, M.E.M. 2003. Origin and structure of the Kranz tissue in bracts of Cyperus giganteus Vahl (Cyperaceae) Revista Brasileira de Botânica 26: 445-452.

Rodrigues, S.; Scremin-Dias, E.; Medeiros, S.C.H. \& Souza, M.C. 2007. Alterações estruturais do caule e da folha de Ludwigia inclinata (L.f.) M. Gómez, desenvolvidos emersos e submersos. Revista Brasileira de Biociências 5: 174-176

Sajo, M.G. \& Castro, N.M.2006. Caule. Pp. 283-302. In: B. Apezzatoda-Glória \& S.M. Carmello-Guerreiro (eds.). Anatomia Vegetal.Viçosa, Editora UFV.

Sculthorpe, C.D. 1967. The biology of aquatic vascular plants. London, Edward Arnold.

Soros, C.L. \& Bruhl, J.J. 2000. Multiple evolutionary origins of $\mathrm{C}_{4}$ photosyntesis in the Cyperaceae. Pp. 629-636. In. K.L.Wilson \& D.A. Morrison (eds.). Monocots: Systematics and Evolution. Melbourne, CSIRO.

Tur, N.M. 1971. Nuevos casos de epifitismo acuático. Bolletim Sociedade Argentina de Botánica 13: 243-249. 